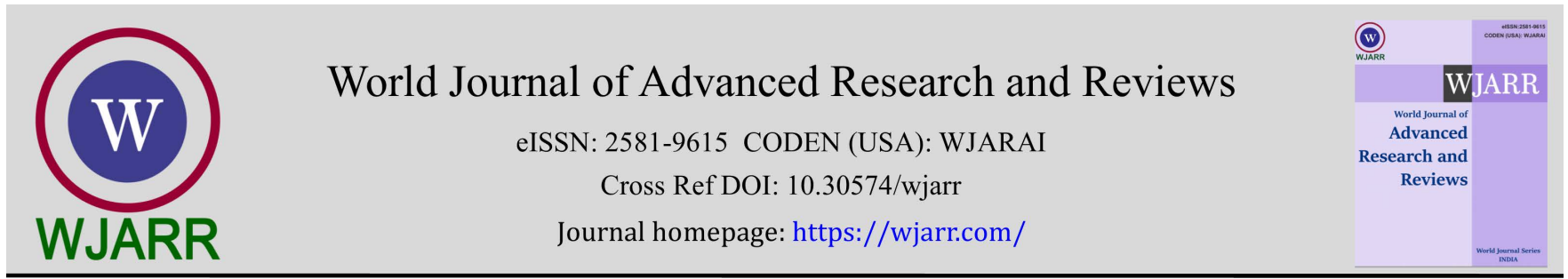

(RESEARCH ARTiClE)

\title{
Participants' Levels of understanding before and after attending the zoom fatigue during COVID-19 Pandemic Webinar
}

\author{
Angelina Vedrika Marciella Tobing ${ }^{1}$, Valensia Irawan ${ }^{1}$, Yusuf Salim ${ }^{1}$ and Sri Wijayanti Sulistyawati 2,* \\ ${ }^{1}$ Faculty of Medicine, Universitas Airlangga, Indonesia. \\ 2 Department of Medical Parasitology, Faculty of Medicine, Universitas Airlangga, Indonesia.
}

World Journal of Advanced Research and Reviews, 2022, 13(01), 338-342

Publication history: Received on 06 December 2021; revised on 07 January 2022; accepted on 09 January 2022

Article DOI: https://doi.org/10.30574/wjarr.2022.13.1.0017

\begin{abstract}
COVID-19 pandemic has become a serious threat to all sectors in the world, contributing in several changes in working approaches as well as human interaction. Since more people have to work from home, video conferencing platforms are becoming more popular. The use of this platform is physically and mentally exhausting; zoom fatigue is a well-known. It turns out that using this platform is more mentally exhausting than conventional face-to-face communication. As a result, we put up a web course in the form of a webinar titled "Improving Mental Health: Overcoming Zoom Fatigue." We conducted research using the cross-sectional study method with primary data on the results of the pre-test and post-test of the webinar. As a result of this research, we have received a large number of people who participated in the webinar, with $92.1 \%$ of them being women, age group 18-25 years by $57.5 \%$, and pre-test = post-test based on three grouping scores, amounting to $57.2 \%$ with an increase in knowledge significant $(\mathrm{p}<0.001)$.
\end{abstract}

Keywords: Webinar; COVID-19; Zoom Fatigue; Pandemic

\section{Introduction}

COVID-19 pandemic has become a major threat to all sectors around the world, causing many changes in work methods as well as human interaction. Most people now study and work on laptop computers. The online learning and work system is not always negative; it has benefits and drawbacks. The online system is acknowledged as requiring careful planning and adaptation in order to attract high-quality employees and students [1]. One of the most common problems encountered by workers and students is the dilemma in which they believe that the home is usually a place of rest, but this has now been reversed, resulting in a lack of flexibility in the family and the flexibility of time [2].

Furthermore, there is a lot of fatigue, particularly in terms of mental health, as a result of work and online learning. According to the WHO survey, there is an increase in access to mental health services worldwide. Depression, Generalized Anxiety Disorder, and Panic Attacks were the most common mental health conditions discovered. The age group of patients who use mental health services the most is the productive age group, which includes those who are actively working, as well as students and workers. This age group is said to be the most vulnerable to stress as a result of their excessive use of social media. Most people of this age frequently complain about video conferencing platforms, which cause fatigue in a variety of ways, both physically and mentally. The most used video conferencing platforms are 'Zoom', 'Webex', 'MS Teams' and 'Skype.' They claim that the side effect of using this platform is excessive fatigue which is usually called zoom fatigue. It turns out that using this platform is more psychologically demanding than usual faceto-face contact. This is due to the increased need to concentrate on interpreting the body language of the interlocutor [3]. In addition, the impact is not focusing on every online meeting because of the continuous and prolonged online

\footnotetext{
${ }^{*}$ Corresponding author: Sri Wijayanti Sulistyawati

Department of Medical Parasitology, Faculty of Medicine, Universitas Airlangga, Indonesia.

Copyright $(2022$ Author(s) retain the copyright of this article. This article is published under the terms of the Creative Commons Attribution Liscense 4.0.
} 
meeting schedule and other activities being carried out simultaneously. There is also a lot of lack of confidence in showing close-ups of faces during online meetings [4].

As a result, representatives from the Faculty of Medicine, Universitas Airlangga, held an activity in the form of a web course, namely an online webinar/seminar. One of the webinars was about mental health, specifically what is currently most common among the productive age group, namely zoom fatigue. This activity is expected to result in them understanding about mental health during a pandemic, what problems can arise during a pandemic, the signs and symptoms of someone experiencing zoom fatigue, the impact of zoom fatigue, and tips for overcoming and avoiding zoom fatigue. According to the webinar, there was a lot of emphasis on Zoom fatigue experienced by workers and students, which could be due to increased use of social media as well as video conferencing errors. Feedback from this activity is also required for the organizers, specifically the evaluation of participants via pretest and posttest. We conducted research based on these two aspects to measure, interpret, and evaluate the webinar results.

\section{Material and methods}

This study is a cross-sectional study that analyzes primary data from webinar participants' responses. The webinar, "Improving Mental Health: Overcoming Zoom Fatigue," will take place online via a zoom meeting. Participants are given time prior to the start of the webinar session to complete a pre-test regarding the webinar material to be presented. Furthermore, the presenters, Dr. Santi Yuliani Sp. KJ, presented quite interesting material beginning with the definition of zoom fatigue, signs and symptoms of zoom fatigue, and tips for preventing and treating these symptoms. Following the material session, there was a question and answer session with the participants, followed by a post-test filling session. Following that, we conducted research in the form of a cross-sectional study analysis using primary data from the answers scores of participants in the webinar, where the sample was taken by total sampling while considering the inclusion criteria, namely participants aged 12-35 years, and filling out the pre-test and post-test. This study was conducted under the auspices of FK UNAIR, with data collection scheduled for July 2021. After all sample data had been taken and compiled, then the participants' scores were grouped with the provision that a score of 0-3 was less; a score of 4-6 is sufficient; and a score of 7-10 is good, so that ordinal data is obtained, which will then be carried out with a Wilcoxon comparison test (SPSS 17.0 application with a significance level of $\mathrm{p}<0.05$ ). then grouping the scores of participants with the provisions of a score of 0-3 is less; a score of 4-6 is sufficient; and a score of 7-10 is good, so that ordinal data is obtained, which will then be carried out with a Wilcoxon comparison test (SPSS 17.0 application with a significance level of $\mathrm{p}<0.05$ ). then grouping the scores of participants with the provisions of a score of 0 -3 is less; a score of 4-6 is sufficient; and a score of 7-10 is good, so that ordinal data is obtained, which will then be carried out with a Wilcoxon comparison test (SPSS 17.0 application with a significance level of $p<0.05$ ).

\section{Results and discussion}

\subsection{Characteristics of participants}

The study sample that met the inclusion criteria was 1421 participants with the highest frequency found in the female sex as many as 1309 participants (92.1\%) and in the late adolescent age group (18-25 years) as many as 818 participants (57.5\%). Along with the another research where the highest awareness of mental health in women and the age vulnerable to psychological disorders are late adolescence to early adulthood with the most symptoms of anxiety and depression [5].

Previous research got the most participants in women with the most age $<30$ years, because of the level of selfawareness of mental health or mindfulness. Mindfulness is one of the topics discussed during the webinar and experienced mostly by women, along with the another research conducted by Katz and Toner who reviewed many journals, where the majority of women were found to be due to awareness to prevent mental disorders. Such as zoom fatigue symptoms. Mindfulness-based interventions provide self-instruction to be able to improve oneself and reduce stress levels as an external response, such as the current pandemic situation [6, 7].

In another study conducted on a population of 10,000 in which one in seven women reported feeling "very" tired after a zoom meeting. Whereas in men, only one in twenty men felt the same way. The reason is thought to be because women see themselves differently than on the monitor screen. So online meetings are considered not as effective as conventional meetings, as they were before the pandemic. From the various reasons previously described, there are strong reasons that most of our webinar participants are women. Not only age and gender are factors in the awareness of mental disorders including zoom fatigue, but there are factors of personality type and these variables can be carried 
out in further research. Introverts and extroverts have different personality types, and introverts are said to be more easily exhausted after online meetings or video conferencing [8].

Table 1 Distribution of participants by age and gender

\begin{tabular}{|l|c|c|}
\hline Category & Frequency & Percentage (\%) \\
\hline Age & 581 & 41 \\
\hline Early teens (13-17 years) & 818 & 57.5 \\
\hline Late teens (18-25 years) & 22 & 1.5 \\
\hline Early adulthood (26-35 years) & \multicolumn{2}{|l|}{} \\
\hline Gender & 112 & 7.9 \\
\hline Man & 1309 & 92.1 \\
\hline Woman & 1421 & 100 \\
\hline Total & & \\
\hline
\end{tabular}

\subsection{Participants' Knowledge Level}

If classified based on the grouping of participants with the results of the less category, there was a decrease from the pre-test by $42.2 \%$ to $28.1 \%$ in the post-test. On the other hand, there was an increase in the score in the good category with the pre-test by $7.4 \%$ to $24.9 \%$ in the post-test. This happened because of the influence of the webinar both in terms of material, speaker delivery and a test was carried out before delivering the material so that the enthusiasm of the participants to get the post-test results was better than the pre-test. In another study, there was also an improvement in the post-test with a significant level of knowledge [6].

Table 2 Categories of pre-test and post-test of Webinar 1 METHADONE FK UNAIR

\begin{tabular}{|l|c|c|c|c|}
\hline Value Category & \multicolumn{2}{|c|}{ Pre-test category } & \multicolumn{2}{c|}{ Post-test category } \\
\hline & Frequency & Percentage (\%) & Frequency & Percentage (\%) \\
\hline Less Category & 599 & 42.2 & 399 & 28.1 \\
\hline Enough Category & 717 & 50.5 & 668 & 47.0 \\
\hline Good Category & 105 & 7.4 & 354 & 24.9 \\
\hline Total & 1421 & 100 & 1421 & 100 \\
\hline
\end{tabular}

In this study, the number of samples with the post-test score category was higher than the pre-test score category of 114 people (8\%), while the number of samples with the post-test score category was lower than the pre-test score category of 494 people $(34.8 \%$, and the number of samples with the same post-test score category as the pre-test score category was 813 people (57.2\%) (Table 2). The highest number of category changes was obtained by post-test = pretest of $57.2 \%$ and followed by post-test $>$ pre-test of $34.76 \%$. In the post-test<pre-test the least, the percentage difference is very much with the other 2 categories.

Table 3 Changes in the category of pre-test and post-test scores of Webinar 1 METHADONE FK UNAIR

\begin{tabular}{|l|c|c|}
\hline Post-test < Pre-test & 114 & $8.02 \%$ \\
\hline Post-test $>$ Pre-test & 494 & $34.76 \%$ \\
\hline Post-test=Pre-test & 813 & $57.2 \%$ \\
\hline Total & 1421 & $100 \%$ \\
\hline
\end{tabular}


Table 4 Wilcoxon correlation test for the categories of pre-test and post-test scores of Webinar 1 METHADONE FK UNAIR

\begin{tabular}{|c|c|}
\hline $\mathrm{Z}$ & $\mathbf{- 1 5 , 6 2 5 b}$ \\
\hline asymp. Sig. (2-tailed) & 0.000 \\
\hline
\end{tabular}

In the Wilcoxon correlation test, it was found that the significance level was $\mathrm{p}<0.001$, so there was a significant difference between the pre-test and post-test categories of the webinar. So it can be said that there is a significant level of knowledge among webinar participants.

In the implementation of this webinar, there are advantages and disadvantages. The advantages obtained are 1) Online implementation so that it can save costs and is affordable for various groups of people in Indonesia 2) Webinars are given free of charge or at no cost so that students and workers from various circles can take part in this activity. The drawbacks of this activity 1) Participants who exceed the target make the committee neglect the division of tasks to manage the event both as admin and other job descriptions 2) Participants' questions are limited due to limited time so that only the best questions are chosen. The obstacles that we do are in conjunction with various studies [9].

\section{Conclusion}

The highest distribution of participants was found in the 18-25 year age group and female. Comparison of the scores obtained from participants before and after the webinar with the theme 'Improving Mental Health: Overcoming Zoom Fatigue' which was evaluated through the results of the pre-test and post-test of $57.2 \%$ with the pre-test value equal to the post-test value. Test, with a significant increase in knowledge level $(\mathrm{p}<0.001)$. In this study, there was a decrease in the frequency of participants in the poor category, from the pre-test to the post-test scores of $42.2 \%$ to $28.1 \%$. On the other hand, there was an increase in the frequency of participants in the good category, from the pre-test to the posttest scores by $7.4 \%$ to $24.9 \%$. As a result, the webinar that was held had a significant influence based on the evaluation results of the participants.

This study can be used as a foundation for future research, particularly in studies that use primary data with a cross sectional study method of pre-test and post-test evaluation. Furthermore, for the community, this research can be used as an intervention material in order to avoid being exposed to Zoom Fatigue. We hope that this research can be expanded in the future by narrowing the age range.

\section{Compliance with ethical standards}

\section{Acknowledgments}

Thank you to the Faculty of Medicine, Universitas Airlangga for facilitating the COVID-19 Module Community Service Program. Thanks are also conveyed to our supervisors during the COVID-19 and to those who have helped in implementing the COVID-19 Module.

\section{Disclosure of conflict of interest}

The authors have no conflicts of interest to declare.

\section{Statement of informed consent}

Informed consent was obtained from all individual participants included in this study.

\section{References}

[1] Galanti T, Guidetti G, Mazzei E, Zappalà S, Toscano F. Work From Home During the COVID-19 Outbreak. Journal of Occupational and Environmental Medicine. 2021; 63(7): e426-e432.

[2] McCloskey DW. An examination of the boundary between work and home for knowledge workers. International Journal of Human Capital and Information Technology Professionals. 2018; 9(3): 25-41. 
[3] Lee J. A Neuropsychological Exploration of Zoom Fatigue [Internet]. 2021.

[4] Williams N.Working through COVID-19: 'Zoom' gloom and 'Zoom' fatigue. Occupational Medicine (Oxford, England). 2021; kqab041.

[5] Van Droogenbroeck F, Spruyt B, Keppens G. Gender differences in mental health problems among adolescents and the role of social support: results from the Belgian health interview surveys 2008 and 2013. BMC psychiatry. 2018; 18(1): 1-9.

[6] Damayanti R. Knowledge Enhancement about COVID-19 Prevention on Community with Webinar Program. Journal of Public Services. 2021; 5(1): 103-110.

[7] Katz D, Toner B. A systematic review of gender differences in the effectiveness of mindfulness-based treatments for substance use disorders. Mindfulness. 2013; 4(4): 318-331.

[8] Elsesser K. 'Zoom Fatigue Is Worse For Women — Here's Why.' [Internet]. 2021.

[9] Aly MN, Putri ANR, Rosyida G, Hamidah A, Ahmad AS, Suryani HA, A'yuni AQ, Khairunnisa PH, Rachmadicha NN, Ilmi IQ. A "NEW NORMAL" SAFE GUIDE TO THE COVID-19 PANDEMIC. Journal of Public Services. 2020; 4(2): 415-422. 